\title{
Evaluation of Websites by Many Criteria Using the Algorithm for Pairwise Comparison of Alternatives
}

\author{
Rasim M. Alguliyev \\ Institute of Information Technology, Azerbaijan National Academy of Sciences, 9A, B. Vahabzada street, AZ1141, \\ Baku, Azerbaijan \\ E-mail: r.alguliev@gmail.com
}

\author{
Gulnara Ch. Nabibayova and Saadat R. Abdullayeva \\ Institute of Information Technology, Azerbaijan National Academy of Sciences, 9A, B. Vahabzada street, AZ1141, \\ Baku, Azerbaijan \\ E-mail: gnabibayova@gmail.com, sado.amea@gmail.com
}

Received: 10 September 2019; Accepted: 16 March 2020; Published: 08 December 2020

\begin{abstract}
The article proposes a comprehensive method for the multicriteria evaluation of websites. The essence of this method is that using this method we can not only evaluate a website traditionally, but also obtain the following useful results: importance coefficient of each of the criteria, the evaluation of the website for each criterion individually. Moreover, we can also compare the sampled websites and then rank them. It is noted that in order to get the precise result, the sampled websites must be referred to the same category, that is, have the same set of criteria for evaluation.
\end{abstract}

Index Terms: Website, website classification, site category, criteria for site evaluation, target audience, expert, web page, site navigation, method, multicriteria website evaluation, algorithm for pairwise comparison of alternatives.

\section{Introduction}

An effective use of modern information technologies, the availability of information resources and the ability to use them professionally ensure the success of any organization. The Internet provides new high-quality opportunities, being a powerful tool for the dissemination of information in a virtual space. The presence of an organization or person on the Internet involves the creation of a website as a key form of information exchange in the global network. Since websites represent the information related to various fields of activity of an organization or an individual, they attract a huge audience and also open up opportunities for solving various marketing and business problems [1].

Since the creation of the world's first website by the British scientist-inventor Tim Berners-Lee in 1991, this technology has begun to develop at a tremendous pace. Currently, a huge number of websites are available on the Internet that belong to various categories according to their purpose. Today, various technologies for the creation of websites are developing and constantly improving [2].

The process of website creation includes the following main steps:

- determination of the goals and objectives, and scheduling;

- design, implementation, information support;

- implementation of a marketing program for a website promotion on the global network;

- evaluation of the quality of the resource and its effectiveness [1].

Thus, website maintenance includes not only keeping it up-to-date, but also regularly implementing the internal monitoring of the website, as well as evaluating it for compliance with the goals and objectives of the organization, modern requirements for web resources by the professional community, and determining how well it satisfies the target audience. It should be noted that it is also recommended to regularly monitor the websites of competitors. This will help to achieve a real assessment of their level, and will also contribute to the development of the resource with unique, distinctive properties [1].

The goal of this article is to develop a comprehensive method for multicriteria evaluation of websites. With its help, we can not only evaluate the website, but also get useful results such as the importance coefficient of each of the criteria, as well as the evaluation of sites for each criterion individually. The application of the algorithm for pairwise 
comparison of alternatives with the participation of experts specialized in this field makes it possible to compare and then rank the sampled websites. It is noted that in order to get the accurate result, the sampled websites must be of the same category, that is, have the same set of criteria for evaluation. The proposed method consists of four stages. Stage 1 calculates the importance coefficient of each of the website criteria using the expert ranking method. Stage 2 evaluates the website by each criterion individually by one expert using the expert method for pairwise comparisons of alternatives. Stage 3 calculates the average value of each website for each criterion individually, taking into account the estimates of all experts. The median function is used for this. Stage 4 calculates the values of the sampled websites by all criteria.

A brief summary of the article is presented below.

The second chapter provides a brief description of several works related to the reviewed topic. The third chapter classifies the websites by various parameters. The fourth chapter presents general and some particular criteria for the evaluation of websites. The fifth chapter comprehensively describes the proposed multicriteria website evaluation method which consists of four stages. The sixth chapter shows the practical application of the proposed method. The Conclusion presents the main results obtained in this article. In addition, the need for the evaluation of websites is mentioned which helps to identify their shortcomings and timely take the necessary measures for their elimination.

\section{Related Works}

A number of articles on website assessment were reviewed.

In [1], the author proposes a method for evaluating university websites. This article proposes a technique in which an individual assessment method is selected. The calculations involve the individual assessments of the opinions of each expert which are summarized in the final assessments for each resource. First, the author determines the parameters of the website and the criteria included in them by which the website will be evaluated. Then the author calculates the weighting coefficients of the criteria and parameters using expert estimates. To obtain the final website score, the values of the parameter with the corresponding weighting factors are summarized.

The article [3] analyzes the approaches to assessing the quality of university Internet resources. It is noted that one of the methods for evaluating university websites is the method of content analysis based on the method of expert assessments. In this case, an assessment of four indicators of the website is proposed: site structure, content, manufacturability and ease of use. Another way of assessing the quality of a site is based on SEO audit (Search Engine Optimization - analysis of website promotion in search engines and directories) and analysis based on web analytics (according to the statistics of visits). First of all, this is the international ranking of Webometrics [4]. This method is calculated by the Cybermetrics research group, which is a part of the National Research Council (CSIC) of Spain. Note that none of these methods is comprehensive and complete.

The article [5] proposes the methods and criteria for evaluating specifically the medical sites. The openness and accessibility of information for the patient are chosen as the criteria for the quality of the website of the medical organization. The aim of this article is to assess the content, information content, accessibility and practical significance of the official websites of medical organizations.

To assess the compliance of medical organizations with the requirements for the content and the form of providing information posted on the official medical websites, a special legislative framework is used. To evaluate the sites, the groups of criteria and the subcriteria in each group are established: on a medical organization, on the rights and obligations of citizens in the field of health care, on the medical activities of a medical organization, on the medical staff of a medical organization, on consumer reviews of services, etc. An expert assessment of information content, accessibility, the functionality of the official websites of the medical organizations is performed using the method of expert evaluations.

\section{Classification of Websites}

A website is a set of web pages linked together by hyperlinks and a single navigation system.

Today, websites and web systems help to successfully solve problems in various fields of human activity, such as transport [6], banking [7], trade [8], etc.

Today, the Internet includes more than 5 billion websites. Their number increases each day. Determining which category a website refers to is crucial. Website classification appropriately categorizes a huge number of websites. Website classification is principally essential for security reasons. Some organizations block entertainment sites, social networks, etc. for security reasons. In addition, the classification of sites is necessary for the correct orientation of the target audience.

Various categories of websites are given below. Their classification is performed by different parameters, as subject, functionality, purpose, and in accordance with the presentation method, access mode, etc.

The classification of websites by subject includes the definition of the areas for the subject of the website. These include business sites, e-commerce sites, social networks, libraries and archives, entertainment, information, news and personal sites, web portals, blogs, etc. Functional classification specifies the purpose of the website. The classification 
by objective defines personal, corporate, media, business, educational, political, sports and entertainment websites, and the websites of institutions and organizations, services, etc. In accordance with the presentation method, the websites are classified as regular ones, as well as the databases, file servers, newsgroups, etc. In accordance with the access mode, the websites represent open (unlimited) information, information with limited access, and confidential information (commercial secret, professional secret, official secret, personal secret) [9, 10].

Depending on the built-in technology, the following types of websites can be distinguished for their functionality and style of design:

- Static websites contain static HTML or XHTML page;

- Dynamic websites - web pages are created or formed in the process of performing user requests either from information stored in the server database, or directly in a web browser.

- $\quad$ Flash sites the main tool of which is vector graphics;

- Combined websites use these three above mentioned technologies [11].

The website evaluation based on the stated criteria will allow for the correct evaluation of its effectiveness.

Analysis of the information presented on the site, when evaluated, provides a general overview of the site. There is no single criterion for adapting information on the sites to any criteria prior to its publication on the Internet. In this regard, criteria can be used to assess the source, reliability, relevance and objectivity of information displayed on websites [12].

\section{General and Specific Criteria for Website Evaluation}

The criteria, by which the websites are evaluated, may be general and private. General criteria do not depend on the category of the site. Private criteria are referred to a specific category of websites.

The general criteria for the website evaluation may include the followings [13-15]:

\subsection{Information about the owners of the resource / authors of the website:}

- Availability of information about the author(s);

- Availability of links to more detailed information about the author or owners;

- Availability of contact information;

4.2. Reliability (accuracy) of information:

- Lack of factual errors;

- Availability of a website editor;

- Availability of links to sources cited;

\subsection{Relevance:}

- Availability of publication dates of the material;

- Lack of broken links;

\subsection{Content:}

- Completeness of information;

- Originality of content;

- Value of information;

4.5. Presentation of information:

- Text structuring;

- Lack of typographical, spelling, grammatical and stylistic errors;

- Use of illustrations as a complement to the text, but not as a distracting element;

4.6. Website Access:

- $\quad$ Fast loading;

- Stability of website address;

- Availability of other versions of website (mobile, for visually impaired people, etc.);

- Availability of information on all pages (in all sections) of website;

- Availability of website statistics for its analysis.

\subsection{Ergonomic use:}

- Logically correct organization of content; 
- Simple and clear navigation;

- Location of navigation in the same place on all pages;

- Opportunity to use navigation to return to previous sublevels;

- Feedback availability and accessibility;

- Clear method to navigate through sequentially linked pages and sections of website;

- Location of the links below, even if they are duplicated elsewhere;

- Availability of a website map;

- Website compatibility with the latest browser editions;

- Opportunity to view the website at several resolutions;

\subsection{Technical implementation:}

- Short page loading time;

- Minimal HTML code;

- Availability of a search engine with expanded search;

- Separation of content from design using CSS files;

- Inclusion of headers and footers in a separate file;

- Inclusion of CSS (cascading style sheets) used in several documents into a separate file;

- Inclusion of JavaScript functions used in several documents into a separate file;

- Use of only digits and lower-case English scripts in the file names and hyperlink addresses, the use of underscore is also permitted.

- Appearance (design):

- Unified style (colors, fonts, graphics) of all pages;

- Color balance of page design;

- Website pages, especially home pages, should not be burdened with information;

- Availability of high-quality graphics.

Note the following criteria for evaluating a website:

- Inclusive website design to help people with disabilities;

- Ensuring information security (resistance to spams, DoS attacks, etc.)

- Availability of transliteration;

- Translation opportunities into other languages.

However, along with general criteria, each category of websites has its own specific criteria.

For example, the website of a government authority should not only provide full information about itself, but also provide information about organizations under its jurisdiction. In addition, the availability of the section "News" on this website is obligatory which usually contains press releases, information on tenders, vacancies, etc. An important requirement for the government's website is the availability of feedback, which includes e-mail, newsletter subscription, questions for public servants, visiting hours, organization of forums and conferences, etc. Moreover, another important requirement is the opportunity to perform network transactions, such as electronic payments, registration for participation in tenders and service delivery, etc.

The article [1] presents the criteria for the websites of higher education institutions. They may include:

- availability of a university business card, which includes a logo, description of the field of activity, historical information, a list of significant achievements, information about the management (rector, vice-rector, dean, etc.);

- availability of distinguishing advantages such as unique equipment and laboratories, integration with leading enterprises of relevant industries and conducting professional training of students based on them, as well as writing theses, availability of training centers and certification of leading companies, participation and achievements in various ratings, and availability of sustainable relations with foreign universities, etc.;

- availability of information for applicants, including the statute and license of the educational institution, a certificate of state accreditation, the plan and rules for admission to the educational institution, working hours of the admission committee, etc.;

- availability of information on additional educational services, such as evening and distance education, postgraduate education, graduate studies, postgraduate and doctoral programs, advanced training programs, etc.;

- availability of information on the educational process, including the availability of class schedule on the site, additional educational materials for students: electronic versions of lectures of training courses, schedules of seminars and laboratory classes, workshops, the availability of an electronic library, access to international databases of scientific information, such as, Elsevier, Springer, Kluver etc.; 
- availability of information about graduates and their employment, namely: statistics of graduates, meetings and graduation events, information from employers, etc.

Requirements for medical websites are particularly important. In order to help users to distinguish trustworthy resources from unreliable resources, Health On the Net Foundation (HON) was established in 1995. This is a non-profit, non-governmental organization accredited by the UN Economic and Social Council (ECOSOC) [16]. HONcode Certification is an ethics standard aimed at providing high-quality medical information. In order to get the certification, an application is first submitted and the organization's logo is uploaded on the site. As soon as the reviewer confirms the full compliance of the website with the principles of HONcode, its logo on the website is activated. The basic principles of the HON Code to be followed are:

- Authorship;

- Purpose of website;

- Confidentiality of information;

- Documented information: source and date;

- Validity of allegations;

- Website contact information;

- Sources of financing;

- Advertising policy.

Media resources are of special status among other Internet resources. The following criteria are proposed as the key criteria through which a media resource is assessed: the adequacy of its domain address, the efficiency and dynamics of posting news, the development of advertising and marketing strategies to increase advertising revenue, the use of the latest software for paid news, the number and professionalism of journalists, the amount of daily information posted on the site, etc.

Note that a full evaluation of websites can be performed, that is, taking into account all criteria, individual blocks of criteria, for example, for its safety, quality design, etc.

The International Organization for Standardization (ISO) has also developed the standards for websites. Among them are the standards for developing an effective and convenient design, as well as for economically grounded usercentered content. Some of them are given below:

- ISO 13407 - Human-centered design processes for interactive systems [17];

- ISO 18529 - Ergonomics of human-system interaction [18];

- ISO 9241-11: 2018 - provides a framework for understanding the concept of usability and applying it to situations where people use interactive systems [19];

- ISO / IEC 40210: 2011 - Information technology - W3C SOAP Version 1.2 Part 1: Messaging Framework (Second Edition) [20];

- ISO / IEC 40500: 2012 (W3C) - Information technology - W3C Web Content Accessibility Guidelines (WCAG) $2.0[21]$.

Note that several regulatory documents on the creation and use of websites have been developed in Azerbaijan. They may include:

- Law of the Republic of Azerbaijan "On obtaining information" (September 30, 2005) [22];

- "National Strategy for the Development of Science in the Republic of Azerbaijan in 2009-2015" (May 4, 2009) [23];

- Decision of the Cabinet of Ministers of the Republic of Azerbaijan on approval of "Requirements on creation and management of Internet information resources of state bodies" (September 4, 2012) [24];

- "National Strategy for Development of Information Society in the Republic of Azerbaijan for 2014-2020" (April 2, 2014) [25].

\section{Method for Multi-Criteria Evaluation of Websites}

To improve the performance of a website, as well as for its continuous improvement, its evaluation is of great importance. The proposed method for multicriteria evaluation of websites with the participation of several experts, who are the specialists in this field, is based on an algorithm for pairwise comparison of many alternatives. Note that the proposed method does not affect its promotion in search engines.

The proposed method for multicriteria evaluation of website contains four stages.

Stage 1 determines the importance coefficient of each $n$ criteria for website evaluation using the ranking method 
with the participation of $t$ experts.

The importance coefficient is a numerical coefficient representing the significance, the relative importance of the criterion in relation with other indicators that affect the process under study.

Assume that there are $n$ criteria for websites' evaluation and $t$ experts, each of which assigns a rank to each criterion in the range from 1 to $n$, with higher ranking being assigned to more important criterion. Then $\left\|a_{l k}\right\|$ is a matrix of ranks assigned to $t$ experts by $n$ criteria, where $a_{l k}$ is the rank assigned to the $k$-th sub-criterion by the $l$-th expert, $l=\overline{1, t}, k=\overline{1, n}$.

Next, the sums of the ranks assigned by all $t$ experts to each $n$ criteria:

$$
a_{k}=\sum_{l=1}^{t} a_{l k}
$$

where $k=\overline{1, n}$.

Then the importance coefficient $w^{k}$ of the $k$-th criterion of the website will be determined as:

$$
w^{k}=\frac{a_{k}}{\sum_{k=1}^{n} a_{k}}
$$

where $k=\overline{1, n}$.

Moreover, we will have

$$
\sum_{k=1}^{n} w^{k}=1
$$

Stage 2 evaluates the website for each criterion individually by one expert. In this regard, the method for pairwise comparisons is applied [26].

The method for pairwise comparisons is based on pairwise comparison of alternatives. In our task, the alternatives are the websites. Comparing in pairs, the expert evaluates by one selected criterion, i.e., for each pair of alternatives the expert indicates which website is preferable by that criterion. Numerous algorithms are available for the implementation of the method for pairwise comparisons: they differ in the number of expert estimations used (individual and collective estimations), and in the scales for comparing alternatives, etc.

Assume that there are $\boldsymbol{v}$ websites that will be assessed on each $n$ criteria. One of the criteria, for example, the $k$-th criteria is chosen.

Each expert fills in a matrix of pairwise comparisons of $v_{x} v$ size where $v$ is the number of websites. The matrix is filled in according to the rules specified by a group of experts. One of the options for filling in the matrix is shown in Table 1. As the table shows, this method uses 5 types of comparisons for two websites.

Table 1. Rules for filling in the matrix of pairwise comparisons

\begin{tabular}{|c|c|}
\hline $\mathrm{a}_{i j}$ & Comparison value \\
\hline 1 & $i$-th and $j$-th websites are approximately equivalent \\
\hline 3 & $i$-th website is slightly preferable to the $j$-th website \\
\hline 5 & $i$-th website is preferable to the $j$-th website \\
\hline 7 & $i$-th website is much more preferable to the $j$-th website \\
\hline 9 & $i$-th website is evidently preferable to the $j$-th website \\
\hline
\end{tabular}

Thus, assume that there are $v$ websites and $s$ experts, and $\left\|a_{r i}^{p k}\right\|$ is a matrix of pairwise comparisons of $v$ websites of one ( $p$-th) expert for one (k-th) of $n$ criteria, where $p=\overline{1, s}, k=\overline{1, n}$. Moreover, $a_{r l}^{p k}=1$ if $r=l$ and $a_{r l}^{p k} \neq 1$ if $r \neq l$.

Further, we determine the estimation of each website by the criterion $k$ of the $p$-th expert.

First, for each $r$-th of $v$ websites, we find the sum of their estimations in pairwise comparison. In this regard, we find the sum of the rows of the comparison matrix:

$$
C_{r}^{p k}=\sum_{l=1}^{v} a_{r l}^{p k}
$$


where $r=\overline{1, v}, p=\overline{1, s}, k=\overline{1, n}$.

And then, the sum of the estimations of the alternative for this criterion for all $v$ websites:

$$
C^{p k}=\sum_{r=1}^{v} C_{r}^{p k}
$$

where $p=\overline{1, s}, k=\overline{1, n}$.

Afterwards, we find an estimation of each $r$-th of $v$ websites by the $k$-th criterion based on the estimations of the $p$ th expert:

$$
V_{r}^{p k}=\frac{C_{r}^{p k}}{C^{p k}}
$$

where $r=\overline{1, v}, p=\overline{1, s}, k=\overline{1, n}$.

Stage 3 calculates the average value of each website for each criterion individually, taking into account the estimates of $s$ experts. The median function is used for this. A characteristic feature of this function is its resistance to "outlines" of values in the set.

The median function returns a value from a sorted set as follows:

- $\quad$ if the number of digits in the set is odd, it returns the value of the central element of the set;

- if the number of digits in the set is even, it returns the average of two central values of element of the set.

Thus, to find the estimate of the $r$-th website by the $k$-th criterion, we have:

where $p=\overline{1, s}, r=\overline{1, v}$.

$$
V_{r}^{k}=\operatorname{median}\left\{V_{r}^{p k}\right\}
$$

It should be noted that the expert is the key source of information when forming the expert evaluation. In addition, to perform the examination, the most competent experts must be selected. However, the competence of experts often differs. To assess the competence of an expert, many factors are taken into account: work experience in this field, research activity, previous work experience in decision-making process, etc. [27]. Expression (7) specifies that the competence of all experts is the same. If the competence of experts differs, i.e. the weight of the $p$-th expert is estimated by the value $e^{P}$, provided that

$$
\sum_{p=1}^{s} e^{p}=1
$$

then (7) will be

$$
V_{r}^{p k}=e^{p} \frac{C_{r}^{p k}}{C^{p k}}
$$

where $r=\overline{1, v}, p=\overline{1, s}, k=\overline{1, n}, e^{p}=\overline{1, s}$.

Stage 4 calculates the values of the sampled websites by all criteria. As noted above, each of the $n$ criteria has its own importance coefficient (2). Thus, evaluation of each website taking into account the importance coefficient of each $n$ criteria will be calculated as follows:

$$
E_{r}=\sum_{k=1}^{n} w^{k} V_{r}^{k}
$$

where $r=\overline{1, v}$.

After that, the websites included in the selection can be ranked according to the values $E_{r}, r=\overline{1, v}$. Moreover, the highest value $E_{r}$ will correspond to the first rank, etc. 
As noted above, when evaluating the websites, it must be taken into account that each category of website has its own set of criteria. Therefore, in order to obtain an adequate result, the websites referring to the same category should be included in the samples for evaluation.

\section{Simulation}

The proposed method for multicriteria evaluation of websites is tested on the example of four websites referring to the same category. For the simplicity of the experiment, it includes three experts and three criteria. The criteria are randomly chosen, as:

1. lack of factual errors;

2. ease of navigation;

3. page loading time.

Stage 1 determines the importance coefficient of each of the three criteria using the ranking method. For this, the experts first assigned the ranks to the criteria at own discretion.

The table of the ranks assigned to three criteria by three experts is as follows (Table 2):

Table 2. Ranks assigned by three experts to three criteria

\begin{tabular}{|c|c|c|c|}
\hline \multirow{2}{*}{ Experts } & \multicolumn{3}{|c|}{ Criteria } \\
\cline { 2 - 4 } & Lack of factual errors & Ease of navigation & Page loading time \\
\hline 1 & 4 & 3 & 2 \\
\hline 2 & 3 & 4 & 1 \\
\hline 3 & 3 & 2 & 1 \\
\hline
\end{tabular}

Based on the table 2 the matrix of ranks assigned to the 3 criteria by three experts will be presented as follows:

$$
\left(\begin{array}{lll}
4 & 3 & 2 \\
3 & 4 & 1 \\
3 & 2 & 1
\end{array}\right)
$$

Then, according to (1), we have:

$$
h_{1}=10 ; h_{2}=9 ; h_{3}=4 ; h=23 \text {. }
$$

According to (2), we obtain the importance coefficients of each criterion:

$$
w^{1}=0,435 ; w^{2}=0,391 ; w^{3}=0,174 .
$$

$t$ the second stage, each of the four websites is estimated according to each of the 3 criteria, starting from the first. Each expert fills in a pairwise comparison matrix of the size $4 * 4$.

Let the evaluation matrices of the four websites by three experts using the pairwise comparisons method for the 1 st, 2nd and 3rd criteria be presented in (12), (13) and (14), respectively:

$$
\left(\begin{array}{cccc}
1 & 3 & 5 & 7 \\
\frac{1}{3} & 1 & 5 & 3 \\
\frac{1}{5} & \frac{1}{5} & 1 & 5 \\
\frac{1}{7} & \frac{1}{3} & \frac{1}{5} & 1
\end{array}\right)\left(\begin{array}{cccc}
1 & 5 & 3 & 7 \\
\frac{1}{5} & 1 & 5 & 5 \\
\frac{1}{3} & \frac{1}{5} & 1 & 5 \\
\frac{1}{7} & \frac{1}{5} & \frac{1}{5} & 1
\end{array}\right)\left(\begin{array}{cccc}
1 & 5 & 3 & 9 \\
\frac{1}{5} & 1 & 5 & 7 \\
\frac{1}{3} & \frac{1}{5} & 1 & 3 \\
\frac{1}{9} & \frac{1}{7} & \frac{1}{3} & 1
\end{array}\right)
$$




$$
\begin{aligned}
& \left(\begin{array}{llll}
\frac{1}{1} & 9 & 7 & 5 \\
\frac{9}{1} & 1 & 3 & 5 \\
\frac{1}{7} & \frac{1}{3} & 1 & 9 \\
\frac{1}{5} & \frac{1}{5} & \frac{1}{9} & 1
\end{array}\right)\left(\begin{array}{cccc}
1 & 9 & 5 & 3 \\
\frac{1}{9} & 1 & 5 & 7 \\
\frac{1}{5} & \frac{1}{5} & 1 & 7 \\
\frac{1}{3} & \frac{1}{7} & \frac{1}{7} & 1
\end{array}\right)\left(\begin{array}{cccc}
\frac{1}{1} & 7 & 3 & 7 \\
\frac{1}{7} & 1 & 5 & 9 \\
\frac{1}{3} & \frac{1}{5} & 1 & 5 \\
\frac{1}{7} & \frac{1}{9} & \frac{1}{5} & 1
\end{array}\right) \\
& \left(\begin{array}{cccc}
\frac{1}{7} & 1 & 3 & 5 \\
\frac{1}{7} & \frac{1}{3} & 1 & 7 \\
\frac{1}{5} & \frac{1}{5} & \frac{1}{7} & 1
\end{array}\right)\left(\begin{array}{cccc}
\frac{1}{1} & 7 & 3 & 5 \\
\frac{1}{7} & 1 & 5 & 5 \\
\frac{1}{3} & \frac{1}{5} & 1 & 7 \\
\frac{1}{5} & \frac{1}{5} & \frac{1}{7} & 1
\end{array}\right)\left(\begin{array}{cccc}
\frac{1}{1} & 7 & 3 & 3 \\
\frac{1}{7} & 1 & 5 & 9 \\
\frac{1}{3} & \frac{1}{5} & 1 & 7 \\
\frac{1}{3} & \frac{1}{9} & \frac{1}{7} & 1
\end{array}\right)
\end{aligned}
$$

Based on these data, according to (4), (5) and (6), the corresponding calculations are performed which are listed in tables 3, 4 and 5 .

Table 3. Score of the four websites by the first criterion based on the estimation of three experts.

\begin{tabular}{|c|c|c|}
\hline $\begin{array}{c}\text { Score of the four websites by the first } \\
\text { criterion based on the estimation of the } \\
\text { first expert }\end{array}$ & $\begin{array}{c}\text { Score of the four websites by the first } \\
\text { criterion based on the estimation of the } \\
\text { second expert }\end{array}$ & $\begin{array}{c}\text { Score of the four websites by the first criterion } \\
\text { based on the estimation of the third expert }\end{array}$ \\
\hline$V_{1}^{11}=0,479$ & $V_{1}^{21}=0,454$ & $V_{1}^{31}=0,482$ \\
\hline$V_{2}^{11}=0,279$ & $V_{2}^{21}=0,318$ & $V_{2}^{31}=0,354$ \\
\hline$V_{3}^{11}=0,191$ & $V_{3}^{21}=0,185$ & $V_{3}^{31}=0,121$ \\
\hline$V_{4}^{11}=0,051$ & $V_{4}^{21}=0,044$ & $V_{4}^{31}=0,043$ \\
\hline
\end{tabular}

Table 4. Score of the four websites by the second criterion based on the estimation of three experts.

\begin{tabular}{|c|c|c|}
\hline $\begin{array}{c}\text { Score of the four websites by the third } \\
\text { criterion based on the estimation of the } \\
\text { first expert }\end{array}$ & $\begin{array}{c}\text { Score of the four websites by the third } \\
\text { criterion based on the estimation of the } \\
\text { second expert }\end{array}$ & $\begin{array}{c}\text { Score of the four websites by the third } \\
\text { criterion based on the estimation of the } \\
\text { third expert }\end{array}$ \\
\hline$V_{1}^{13}=0,511$ & $V_{1}^{23}=0,43$ & $V_{1}^{33}=0,357$ \\
\hline$V_{2}^{13}=0,233$ & $V_{2}^{23}=0,299$ & $V_{2}^{33}=0,386$ \\
\hline$V_{3}^{13}=0,216$ & $V_{3}^{23}=0,229$ & $V_{3}^{33}=0,217$ \\
\hline$V_{4}^{13}=0,039$ & $V_{4}^{23}=0,041$ & $V_{4}^{33}=0,04$ \\
\hline
\end{tabular}

Table 5. Score of the four websites by the third criterion based on the estimation of three experts.

\begin{tabular}{|c|c|c|}
\hline $\begin{array}{c}\text { Score of the four websites by the } \\
\text { second criterion based on the } \\
\text { estimation of the first expert }\end{array}$ & $\begin{array}{c}\text { Score of the four websites by the second } \\
\text { criterion based on the estimation of the second } \\
\text { expert }\end{array}$ & $\begin{array}{c}\text { Score of the four websites by the second } \\
\text { criterion based on the estimation of the third } \\
\text { expert }\end{array}$ \\
\hline$V_{1}^{12}=0,51$ & $V_{1}^{22}=0,437$ & $V_{1}^{32}=0,438$ \\
\hline$V_{2}^{12}=0,211$ & $V_{2}^{22}=0,319$ & $V_{2}^{32}=0,368$ \\
\hline$V_{3}^{12}=0,243$ & $V_{3}^{22}=0,204$ & $V_{3}^{32}=0,159$ \\
\hline$V_{4}^{12}=0,035$ & $V_{4}^{22}=0,039$ & $V_{4}^{32}=0,035$ \\
\hline
\end{tabular}

Based on (7), the corresponding calculations are performed which are listed in table 6.

Table 6. Assessment of each of the four websites by each of the three criteria.

\begin{tabular}{|c|c|c|c|}
\hline $\begin{array}{c}\text { Assessment of the first website } \\
\text { by each of the three criteria }\end{array}$ & $\begin{array}{c}\text { Assessment of the second } \\
\text { website by each of the three } \\
\text { criteria }\end{array}$ & $\begin{array}{c}\text { Assessment of the third } \\
\text { website by each of the three } \\
\text { criteria }\end{array}$ & $\begin{array}{c}\text { Assessment of the fourth } \\
\text { website by each of the three } \\
\text { criteria }\end{array}$ \\
\hline$V_{1}^{1}=0,479$ & $V_{2}^{1}=0,318$ & $V_{3}^{1}=0,185$ & $V_{4}^{1}=0,044$ \\
\hline$V_{1}^{2}=0,319$ & $V_{2}^{2}=0,319$ & $V_{3}^{2}=0,204$ & $V_{4}^{2}=0,035$ \\
\hline$V_{1}^{3}=0,299$ & $V_{2}^{3}=0,299$ & $V_{3}^{3}=0,217$ & $V_{4}^{3}=0,04$ \\
\hline
\end{tabular}


Assessment of each of the four websites, taking into account its assessment by each of the three criteria, is found according to (10):

$$
\begin{aligned}
& E_{1}=V_{1}^{1} w^{1}+V_{1}^{2} w^{2}+V_{1}^{3} w^{3}=0,385 \\
& E_{2}=V_{2}^{1} w^{1}+V_{2}^{2} w^{2}+V_{2}^{3} w^{3}=0,315 \\
& E_{3}=V_{3}^{1} w^{1}+V_{3}^{2} w^{2}+V_{3}^{3} w^{3}=0,198 \\
& E_{4}=V_{4}^{1} w^{1}+V_{4}^{2} w^{2}+V_{4}^{3} w^{3}=0,04
\end{aligned}
$$

Obtaining these results, the sites can be ranked. Thus, in the stated example, the first website was rated the highest, and the fourth one was rated the lowest.

\section{Conclusion}

The article proposes a comprehensive method for multi-criteria website assessment, which solves the following tasks: full assessment of websites, evaluation of websites by specific criteria, comparison and ranking of sampled websites.

Note that the National Academy of Sciences of Azerbaijan includes about 40 research institutes. Each institute has its own website. In the future, a decision support system (DSS) will be developed. DSS will include the proposed method for the monitoring of these websites. Decision makers will be able to evaluate these websites, identify their weaknesses by separate criteria, rank and analyze these websites to identify the problems. The monitoring results will be the basis for the modernization and, possibly, the development of a new website.

In order to minimize the subjectivity in the evaluation of websites, in addition to experts, a wider audience can be involved in the evaluation process through online forums.

Note that website evaluation is a component of a set of implementations aimed at improving the website's efficiency and its promotion on the Internet.

\section{References}

[1] Makarets A.B. Methodology for assessing the quality of marketing communications of university websites // Open Education, 2009, No. 4, 45-56.

[2] Types and forms of websites. How to choose? https://kodolex.com/en/blog/web/website-types/

[3] Poluboyarov V.V. Ratings of university sites as a tool for external assessment of the situation of the educational organization in the formation of management strategies. SCIENTIFIC NOTES. Series History. Political science. Economy. Informatics. 2014 No. 15 (186). Issue 31/1. https://cyberleninka.ru/article/n/reytingi-saytov-vuzov-kak-instrument-vneshney-otsenkipolozheniya-obrazovatelnoy-organizatsii-pri-formirovanii-strategii-upravleniya

[4] Ranking Web of Universities. http://www.webometrics.info/

[5] Khodakova OV, Yevstafyeva Yu.V. Comprehensive assessment of official websites of medical organizations. Health care of the Russian Federation, Russian journal. 2016; 61 (2)/ https://cyberleninka.ru/article/n/kompleksnaya-otsenka-ofitsialnyhsaytov-meditsinskih-organizatsiy

[6] Reuben Alfred, Shubi F. Kaijage. Design of an Integrated Android Mobile Application and Web-Based System (IAMAWBS) as a Solution to Concerns of Passengers Using Bus Rapid Transit System for Public Transportation in Dar Es Salaam // I.J. Information Technology and Computer Science, 2019, No. 2, pp. 30-37.

[7] Ishaq O. Oyefolahan, Aishat A. Sule, Solomon A. Adepoju, Faiza Babakano. Keeping with the Global Trends: An Evaluation of Accessibility and Usability of Nigerian Banks Websites // I.J. Information Engineering and Electronic Business, 2019, No. 2, pp. 44-53.

[8] Oleg Pursky, Dmytro Mazoha. Architecture Model of Integrated Web-based Etrading Business Process Management System // I.J. Information Engineering and Electronic Business, 2018, No. 2, pp. 1-8.

[9] The concept and classification of information resources. Structure in management information support, https://studfiles.net/preview/6266132/

[10] Market analysis - types of sites, http://www.imagos.ru/uslugi.php?id=1010\#12

[11] Types of sites, http://seoklub.ru/tipy_saitov.html

[12] Evaluation criteria for Internet resources, https://uchebniki-besplatno.com/didaktika_1434/kriterii-otsenki-internet-58647.html

[13] Criteria for assessing websites, http://www.i2r.ru/static/255/out_17474.shtml;

[14] Kubasheva E.S., Gavrilov A.G. Methodology for assessing the quality of web applications // Software systems and computational methods, 2013, No. 1 (2), pp. 28-34

[15] Evaluation of university websites. Novosibirsk State Technical University, http://www.nstu.ru/staff/eguide/evaluatingweb/\#1

[16] HON Code Principles // Health On the Net Foundation 
[17] ISO 13407 - Human-centred design processes for interactive systems, https://www.iso.org/standard/21197.html

[18] ISO 18529 - Ergonomics of human-system interaction, https://www.iso.org/standard/33499.html

[19] ISO 9241-11:2018 Ergonomics of human-system interaction - part 11: Usability: Definitions and concepts, https://www.iso.org/obp/ui/\#iso:std:iso:9241:-11:ed-2:v1:en

[20] ISO / IEC 40210: 2011 - Information technology - W3C SOAP Version 1.2 Part 1: Messaging Framework (Second Edition), https://www.iso.org/standard/58335.html

[21] ISO / IEC 40500: 2012 (W3C) Information technology - W3C Web Content Accessibility Guidelines (WCAG) 2.0, https://www.iso.org/standard/58625.html

[22] Law of the Republic of Azerbaijan "On obtaining information" (September 30, 2005), http://www.eqanun.az/framework/11142

[23] "National Strategy for the Development of Science in the Republic of Azerbaijan in 2009-2015" (May 4, 2009), http://www.eqanun.az/framework/17199

[24] Decision of the Cabinet of Ministers of the Republic of Azerbaijan on approval of "Requirements on creation and management of Internet information resources of state bodies" (September 4, 2012), http://e-qanun.gov.az/framework/24256

[25] "National Strategy for Development of Information Society in the Republic of Azerbaijan for 2014-2020" (April 2, 2014), https://president.az/articles/11312

[26] Saati T.L. Making decisions. Hierarchy Analysis Method. M.: Radio and communications, 1993, 278 p.

[27] Petrichenko G.S., Petrichenko V.G. Methodology for assessing the competence of experts // Electronic scientific journal KubSAU, 2015, No. 109 (05), http://ej.kubagro.ru/2015/05/pdf/04.pdf

\section{Authors' Profiles}

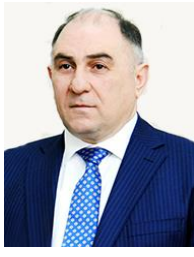

Rasim M. Alguliyev is director of the Institute of Information Technology of Azerbaijan National Academy of Sciences (ANAS) and Vice-President of ANAS.

$\mathrm{He}$ is full member of ANAS and full professor. He received BSc and MSc in electronic computing machines from the Azerbaijan Technical University in 1979. He received his PhD and Doctor of Science (higher degree after $\mathrm{PhD}$ ) in Computer Science in 1995 and 2003, respectively. His research interests include: Information Security, Egovernment, Data Mining, Big Data, Online Social Network Analysis, Cloud Computing, Evolutionary and Swarm Computation, and Scientometrics. He is an author of more than 577 papers, 4 monographs, 4 patents, several books.

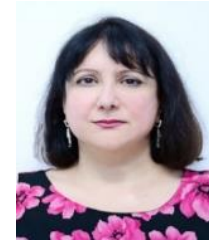

Gulnara Ch. Nabibayova is Head of the Department of the Institute of Information Technology of ANAS. She graduated from the Faculty of Mathematics and Mechanics of Azerbaijan State University (ASU). After graduating from the university, she worked as a developer at the Institute of Cybernetics of the Academy of Sciences of Azerbaijan. Her areas of interest are research in the field of web technologies, data warehousing, OLAP and Data Mining technologies, peer review methods, decision support systems. The research results are applied in the EAzerbaijan State Program. She is PhD in technical sciences. She is an author of more than 20 papers.

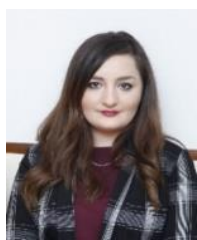

Saadat R. Abdullayeva is graduated from the Baku State University, Faculty of Journalism. She got a master's degree in Journalism at Baku State University. In 2014, she entered a doctoral degree program at the Faculty of Journalism of Baku State University. She is working at the Institute of Information Technology of Azerbaijan National Academy of Sciences as a scientific researcher at the Public Relations Department. Her research interests include: online media, social media, media monitoring, media evaluation, media management, web analytics, web statistics. Her doctoral thesis is "Development of online media monitoring and evaluation mechanisms".

How to cite this paper: Rasim M. Alguliyev, Gulnara Ch. Nabibayova, Saadat R. Abdullayeva, "Evaluation of Websites by Many Criteria Using the Algorithm for Pairwise Comparison of Alternatives", International Journal of Intelligent Systems and Applications(IJISA), Vol.12, No.6, pp.64-74, 2020. DOI: 10.5815/ijisa.2020.06.05 